\title{
Gansos volando en forma de V: construcción de comunidad, eficacia colectiva y espacio defendible en un barrio de Cali, Colombia*
}

\author{
Javier Alexander Molina Correa ${ }^{* *}$
}

Recibido: 5 de enero de 2018

Evaluado: 5 de marzo 2018

Aceptado: 16 de abril de 2018

\section{Resumen}

La ciudad de Santiago de Cali en Colombia se ha caracterizado desde inicios de siglo, por ser una de las urbes más inseguras del mundo. Ante la incapacidad del Estado en la garantía del orden, existen iniciativas desde las comunidades en las cuales se busca mitigar la ausencia de seguridad con acciones colectivas donde se suple esta falencia institucional. Este trabajo busca explorar la experiencia del barrio Marco Fidel Suárez, una de las comunidades con menos muertes de la ciudad gracias a estrategias como el encerramiento voluntario a través de la instalación de enrejados en puntos estratégicos, la regulación de entrada y salida de residentes en anexo a actividades diseñadas e implementadas desde la Junta de Acción Comunal, en aras de la gestión de una convivencia pacífica. Se utilizan: las teorías de la "eficacia colectiva" de Robert Sampson, el "espacio defendible" de Oscar Newman y la adecuación del concepto de emulación de "espacios residenciales multifamiliares", apoyado en herramientas metodológicas cualitativas como la entrevista y la observación pasiva, con el fin de comprender y explicar el desarrollo de las estrategias mencionadas.

Palabras clave: barrio, Cali, comunidad, eficacia colectiva, espacio defendible, espacios residenciales multifamiliares.

\footnotetext{
Artículo de investigación derivado del seminario: "Método de Análisis Etnográfico" coordinado por la Dra. Natalia Suárez Bonilla en el Programa Académico de Estudios Políticos y Resolución de Conflictos. Instituto de Educación y Pedagogía de la Universidad del Valle, Cali, Colombia. DOl: http:/l dx.doi. org/10.15332/ s1794-3841.2018.0029.07

* Profesional en Estudios Políticos y Resolución de Conflictos. Estudiante de la Maestría en Ciencias Sociales de la Universidad Autónoma del Estado de Morelos, México. Becario de investigación del Consejo Nacional de Ciencia y Tecnología - Conacyt. Código Postal: 62748. Correo electrónico: javieralexandermolina@outlook.com
} 


\section{Geese flying in a V shape: community building, defensible space and collective efficacy in a neighborhood of Cali, Colombia}

\begin{abstract}
The city of Santiago de Cali in Colombia has been characterized since the beginning of the century as one of the most insecure cities in the world. Given the State's inability to guarantee order, there are initiatives from the communities in which they seek to mitigate the absence of security with collective actions thus replacing this institutional failure. This work seeks to explore the experience of the neighborhood Marco Fidel Suarez, one of the communities with fewer deaths in the city thanks to strategies such as voluntary enclosure through the installation of fences in strategic points, regulation of entry and exit of residents in addition to activities designed and implemented by the Community Action Board in order to manage a peaceful coexistence. The theory of "Collective Efficacy" by Robert Sampson, Oscar Newman's "Defensible Space" and the adaptation of the concept of "Multifamily Residential Spaces" are used, supported by qualitative methodological tools such as interview and passive observation in order to understand and explain the development of the mentioned strategies.
\end{abstract}

Keywords: Cali, community, collective efficacy, defensible space, multifamily residential spaces, neighborhood.
Received: January 5, 2018

Evaluated: March 5, 2018

Accepted: April 16, 2018 


\section{Gansos voando em forma de V: construção de comunidade, eficácia coletiva e espaço defensável em um bairro de Cali, na Colômbia}

Recebido: 5 de janeiro de 2018

Abaliado: 5 de março de 2018

Aceito: 16 de abril de 2018

\section{Resumo}

A cidade de Santiago de Cali, na Colômbia, tem sido caracterizada desde o início do século, por ser uma das cidades mais inseguras do mundo. Dada a incapacidade do Estado na garantia de ordem, há iniciativas das comunidades em que se busca mitigar a ausência de segurança com ações coletivas em que esse insucesso institucional é substituído. Este trabalho procura explorar a experiência do bairro Marco Fidel Suárez, uma das comunidades com menos mortes na cidade graças a estratégias como o confinamento voluntário através da instalação de grades em pontos estratégicos, que regulamenta a entrada e saída dos moradores além de atividades concebidas e implementadas pelo Community Action Board, a fim de gerenciar uma coexistência pacífica. São usados: a teoria da "eficácia colectiva" de Robert Sampson, o "espaço defensável" Oscar Newman e a adequação do conceito de emulação "espaços multifamily residenciais", apoiado por instrumentos metodológicos qualitativos, tais como entrevista e observação passiva, a fim de compreender e explicar o desenvolvimento das estratégias mencionadas.

Palavras-chave: vizinhança, Cali, comunidade, eficácia coletiva, espaço defensável, espaços residenciais multifamiliares. 
"La ciencia ha descubierto que los gansos vuelan formando una $V$, porque cuando cada pájaro bate sus alas, produce un movimiento en el aire que ayuda al ganso que va detrás de él. Volando en $V$, toda la bandada aumenta por lo menos un 71 por ciento más su poder de vuelo que si cada pájaro lo hiciera solo".

Alonso Lobo Maya - "El vuelo de los gansos"

\section{INTRODUCCIÓN}

La ciudad de Cali, es la tercera urbe más importante de Colombia y una de las más inseguras del mundo desde comienzos del presente siglo. Según cifras del Consejo Ciudadano Para la Seguridad Pública y la Justicia Penal de México (2017, p. 3), este municipio ocupó en el año 2016 el puesto 21 entre las 50 ciudades más violentas del mundo, con 1358 homicidios en medio de una densidad poblacional totalizada en 2 514759 habitantes. Dicha ubicación es la más alejada de los últimos años, puesto que su establecimiento tradicional se acentúa entre las primeras 10 posiciones ${ }^{1}$.

Es perentorio afirmar que Colombia es un país que durante gran parte de su historia ha estado inmerso en un profundo conflicto armado interno. No obstante, la ciudad de Cali no es un territorio afectado directamente por el mismo, dado su alto nivel de urbanización. Su inseguridad está ligada a factores aledaños a la transición de pandillas

Para el año 2015 Cali ocupaba el puesto 10 entre las ciudades más inseguras (Las2orillas, 2016); en el 2014 el puesto 9 (Caracol Radio, 2015); en el 2013 el puesto 7 (El Espectador, 2013), en el 2012 el puesto 11 (Belalcázar, 2012); mientras que en el 2010 ocupaba el puesto 6 (Ortega, 2010). (conformadas en su mayoría por jóvenes) al crimen organizado. En 17 de las 22 comunas hay presencia de estas organizaciones que exacerban los niveles de violencia a través del hurto callejero, el sicariato y las disputas territoriales desde 'fronteras invisibles' ${ }^{2}$ (El País, 2014). En la Figura 1, se destaca la distribución de las pandillas en Cali para el año 2013. De acuerdo a estimaciones, para el 2022 la ciudad tendrá un aproximado de 204 pandillas.

Sin duda, la complejidad de las problemáticas enunciadas exige un seguimiento sistemático de disciplinas relacionadas con los asuntos públicos. Principalmente, las ligadas a los estudios de evaluación de políticas de convivencia ciudadana, con el fin de determinar avances y retrocesos en lo implementado por las distintas administraciones municipales, puesto que la situación esbozada, más que coyuntural es histórica ${ }^{3}$.

2 "Las fronteras invisibles en algunos barrios de Cali expresan la disputa entre pandillas por el control territorial. Quienes saben de su existencia, conocen también que si quieren sobrevivir no pueden atravesarlas. Se trata de lugares que están en poder de un grupo que tiene acceso a las armas, en el que el espacio público transitable es limitado y la violencia que ejercen los que tienen el control es indiscriminada. Por cuenta de estas fronteras invisibles sus habitantes no se pueden mover libremente de un barrio a otro o de una cuadra a otra y muchos tienen que cambiar sus rutinas o dejar las visitas a amigos y familiares del otro lado de la frontera para no poner en riesgo sus vidas" (Borré et.al., 2014, p. 1).

3 Desde la década de los ochenta, los indicadores de violencia en Cali presentan una tendencia al alza. Asentamientos de desmovilizados de la guerrilla del M-19 y acciones colectivas de "limpieza social" donde se asesinan homosexuales, indigentes y trabajadoras sexuales fueron tendencia en esta etapa. En los noventa el apogeo del "Cartel de Cali" encabezado por los hermanos Rodríguez Orejuela, fue una tendencia que después se vio dirimida tenuemente gracias a políticas de desarme impulsadas por el Gobierno. No obstante, la sombra de este fenómeno repercutió hasta principios de siglo. En la actualidad, la violencia se ramifica gracias a frentes que se enlazan a través de un problema de antaño: la droga. La delincuencia organizada encargada de expender, se disputa por territorios, aunado a fenómenos como el pandillismo, el sicariato y las oficinas de cobro. Estos factores hacen de Cali una ciudad que soporta una compleja red generadora de violencia (Naciones Unidas, 2006). 


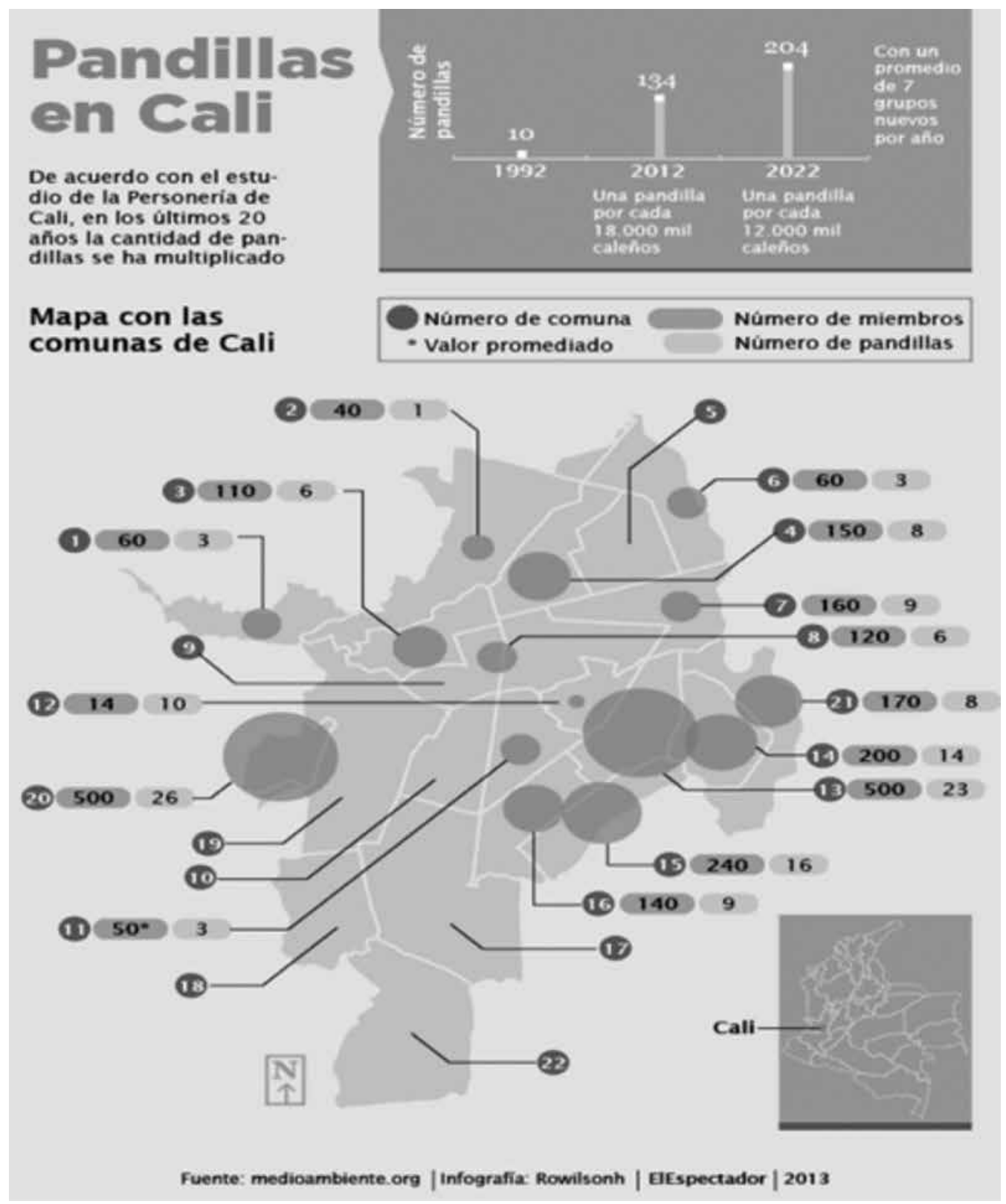

Figura 1. Mapa-infografía de pandillas en Cali

Fuente: El Espectador (2013). 
Sin embargo, esa no será la intención del presente artículo. La discusión que se pretende provocar, está encaminada a reconocer la importancia de la agencia ${ }^{4}$ como generadora de accionares enfilados a enfrentar las vicisitudes propias de la violencia estructural no mitigada por las entidades gubernamentales. En otras palabras, se pretenden conocer las estrategias empleadas por las comunidades para lograr promover una cultura de convivencia pacífica al interior de escenarios de conflicto e inseguridad.

La teoría orientadora del estudio será la de la "eficacia colectiva" de Robert Sampson. En esta se parte de un principio básico: las comunidades tienen la capacidad de construcción de lazos sociales enfilados a reedificar la cohesión social con el objetivo de mantener el bienestar, la seguridad, el control y el orden (Alcaldía de Santiago de Cali, 2007). A su vez, se ampliará el nivel de discusión propuesta con la teoría intermedia del "espacio defendible" de Oscar Newman (1972).

Bajo esta premisa, se tiene como comunidad protagonista de estudio al barrio Marco

4 La concepción de agencia de la que se habla es la derivada de la sociología. La misma, se inserta en una discusión epistemológica que no es nueva y que se apoya sobre el enfoque que escoge el investigador a la hora de aproximarse a los fenómenos sociales. Algunas posturas teóricas como el funcionalismo, el estructuralismo y el viejo institucionalismo plantean que la sociedad debe ser estudiada desde el contexto, desde su estructuración o desde las instituciones sociales (Estado, familia, trabajo, etc.) que moldean la conducta. De esta manera, el comportamiento individual es resultado de lo aprendido y lo aceptado normativamente por el conjunto (ya sea a través de leyes, 0 de códigos morales). Por su parte, la agencia le da mayor capacidad de acción al individuo dotándolo de habilidades racionales o emocionales para hacer sus propias elecciones. De hecho, en esta postura analítica ya no se habla de individuos, sino de sujetos. Hoy día, esta discusión ha mermado su tensión, tras la búsqueda de conjugar ambas propuestas buscando ampliar el nivel explicativo del sociólogo, combinando atributos de parte y parte (Bourdieu, 1991). No obstante, para efectos de este artículo, se hará hincapié en las acciones que diseñan e implementan los sujetos para transformar los contextos de inseguridad y violencia en los que habitan.
Fidel Suárez (en adelante BMFS), ubicado en la comuna 4 en el norte de la ciudad. Se tomó como referente de estudio, por ser uno de los 78 barrios sin homicidios en Cali de los 338 legalmente constituidos para el año 2004. Adicionalmente, era uno de los 12 barrios que había desarrollado estrategias comunitarias de seguridad para el mantenimiento de la paz dentro de su territorio (Tejeda, 2006).

Posteriormente, al indagar sobre los accionares empleados, llamó especialmente la atención, que la forma de mantener el orden, fue el encerramiento voluntario como formato de emulación de conjuntos residenciales o lo que Maldonado y Rincón (2007) denominan: espacios residenciales multifamiliares, concepto que será desarrollado en el apartado final del presente documento.

De esta manera, a través de la instalación de enrejados que se abren durante el día y se cierran durante la noche, con el objetivo de regular la entrada y salida de los habitantes del barrio, se dio génesis a procesos de vigilancia y emprendimientos donde la comunidad desempeñaba roles policivos (Tejeda, 2006).

La eficacia de estas actividades, son reproducidas en informes oficiales posteriores de la Alcaldía de Santiago de Cali (2007a, 2007b). Para el año 2017, el BMFS se mantiene alejado de aquellos donde se produce el mayor número de homicidios de la ciudad (Cali Como Vamos, 2017). En este orden de ideas, el presente artículo se configura como un estudio exploratorio que parte de la siguiente pregunta de investigación: ¿Cómo ha sido el proceso de construcción de estrategias comunitarias de seguridad del BMFS que lo han situado como uno 
de los barrios más seguros de la ciudad de Santiago de Cali?

Por su parte, la hipótesis, que sirvió como supuesto orientador del proceso investigativo fue: La emulación de "espacios residenciales multifamiliares", aunados al empleo de categorías de "eficacia colectiva" y "espacio defendible", son determinantes para generar y mantener la convivencia pacífica del BMFS 5 .

De acuerdo a las características de la pregunta, la investigación se soportó en el uso de métodos cualitativos desarrollados en dos etapas. En la primera, se utilizó observación pasiva con el objetivo de determinar las características propias del contexto y el funcionamiento de los enrejados. En la segunda, se reconstruyó la historia del proceso de planeación e instalación de estas estrategias de seguridad, en conjunto con un análisis evaluativo de logros y falencias a través de entrevistas semiestructuradas a los líderes comunales del BMFS. Aunado a este emprendimiento, se realizó una segunda entrevista a la presidenta de la Junta de Acción Comunal (JAC en adelante) ${ }^{6}$ del barrio Antonio Nariño (BAN en adelante), uno de los más peligrosos de la ciudad, figurando como antinomia de la comunidad protagonista de estudio con el objetivo de

5 La hipótesis tiende a cambiar de acuerdo al paradigma del cual se parta para construir conocimiento. Si se parte desde el positivismo, la hipótesis debe ser formulada desde el diseño de investigación con el objetivo de ser falseada o comprobada. En el caso de paradigmas más comprensivistas (que es la categoría en la cual se ubica este trabajo), donde se parte del análisis de instrumentos de carácter predominantemente cualitativos, la hipótesis no es más que una coordenada orientadora del estudio que puede cambiar a medida que este se va desarrollando. Para efectos del presente artículo, la hipótesis que se sitúa es la que se consolidó como definitiva.

6 Entiéndase como el gobierno del barrio. Vecinos elegidos democráticamente por la comunidad para velar por los intereses de los residentes. comparar accionares encaminados al mantenimiento de la seguridad.

Así pues, la estructura del artículo se soportará inicialmente en la descripción de los insumos sustanciales de la teoría de la eficacia colectiva y el espacio defendible, sumado a la forma en como estas han sido abordadas empíricamente por otros autores hispanoamericanos a través de un estado de la cuestión ${ }^{7}$. Posteriormente se situarán en un mismo escenario, elementos descriptivos y contextuales de la aproximación cualitativa, en conjunto con una puesta en relación de la evidencia empírica con las categorías construidas a través de la teoría. Por último, en las consideraciones finales, se reflexionará sobre la particularidad de la realidad estudiada, el alcance de la teoría de la eficacia colectiva y las aportaciones que realiza al concepto de paz imperfecta ${ }^{8}$, para finalmen-

7 Es perentorio denotar la oportuna diferencia que Esquivel Corella (2013) establece entre estado de la cuestión, estado del arte, estado del conocimiento y revisión documental. El primero, es explicado como la búsqueda de lo que otros han producido sobre el objeto de investigación, tema o problema. El segundo por su parte, es la organización y sistematización de manera novedosa sobre un campo en específico. Evalúa principios y tendencias de un "gran tema" en sus distintas dimensiones espaciales, haciendo hincapié en las investigaciones recientes. El tercero es definido como una idea sucinta y cabal del estado actual de los conocimientos en un campo. Finalmente, la revisión documental busca familiarizarse con un tema de estudio desconocido, siendo el más flexible de los métodos mencionados. De esta manera, no fue intensión del presente proyecto, construir todo un estado del arte, dado que solo se tuvieron en cuentas algunas investigaciones recientes para conocer cómo ha sido abordado el concepto de eficacia colectiva por investigadores hispanoamericanos.

8 Entiéndase como paz imperfecta, en palabras de Francisco Muñoz (2004), todos los espacios y experiencias en los cuales los conflictos se regulan pacíficamente. Su calificativo de imperfecta se desprende de la situación propia en la que está inmersa: el conflicto y la violencia. Por lo tanto, la paz es una construcción dinámica, incompleta e inacabada que convive con sus opuestos. Esta propuesta surge como alternativa al concepto de paz positiva, la cual concibe la paz como ausencia de violencia directa, estructural y cultural, lo que le resta capacidad operativa al concepto, puesto que es muy complejo encontrar algún escenario similar en la realidad. 
te, cerrar destacando la importancia de los estudios de la agencia para la formulación de programas de política pública en América Latina.

\section{Coordenadas TEÓRICO-CONCEPTUALES}

El concepto de comunidad, como la mayoría en ciencias sociales, ha sido objeto de debates múltiples e históricos para su definición. Liceaga (2013) hace un interesante recuento de cómo se ha venido construyendo este concepto desde autores clásicos hasta contemporáneos (de la sociología principalmente), destacando la falta de aportación de América Latina para explicar la particularidad de sus comunidades.

Hay dos elementos que recalcan en el abordaje de los clásicos. Por un lado, la necesidad de acentuar la diferencia entre el concepto de comunidad con sociedad, y por otro, la influencia del sistema socioeconómico capitalista en el forjamiento de comunidades mucho más consolidadas. En su exposición, es marcado el consenso entre Durkheim y Tonnies, destacando la comunidad como "hito inicial" que abrió el camino a la sociedad moderna. En Weber por el contrario, la comunidad está contenida dentro de la sociedad, pues es la arena sobre la cual se soportan las interacciones individuales.

Marinis por su parte, hace una distinción entre la comunidad como categoría analítica (relación teoría-praxis y la comunidad utópica (normativa). La primera caracterizada por la determinación de relaciones interindividuales de calidez, proximidad y estabilidad. La segunda, como aquella alejada de la influencia de "los males propios de la racionalidad capitalista" (Liceaga, 2013, p. 64). Sin duda, por esta línea de pensamiento se encuentra Marx; si bien este nunca empleó el concepto, deja entrever en su entramado argumental que la comunidad es lo contrario al individualismo y la apología a la propiedad privada propia de las relaciones sociales, donde la clase burguesa es la poseedora de los medios de producción.

Por su parte, el concepto de comunidad en América Latina se ha configurado como un nicho donde la singularidad y lo común convergen en un mismo escenario. Generalmente es empleado para referirse a indígenas $\mathrm{u}$ otras minorías étnicas. $\mathrm{Al}$ respecto, Liceaga (2013) afirma:

La palabra comunidad suele utilizarse para denotar formas de agrupamiento humano que, aun con enormes diferencias entre sí (no menores que las que separan a las múltiples, diversas y, en términos de René Zabaleta, “abigarradas" culturas campesinas e indígenas), se encuentran alrededor de ciertos puntos coincidentes, entre los que sobresalen la utilización común de la tierra y/o el agua, instancias de trabajo compartido en algunos momentos del año o en ciertas situaciones vitales y la pertenencia a un mismo grupo lingüístico (p. 6)

Con lo esbozado, queda en evidencia la poca precisión del concepto en tanto su consenso académico y por ende, sus formas teórico-metodológicas de abordaje. Al respecto, Mateo y Quintero (2013) catalogan a la comunidad como un concepto complejo y multidimensional, que en disciplinas donde es protagonista, como en el trabajo social, es más un insumo discursivo, 
ideológico y potencializador de la integración. Además, estimula el forjamiento de las relaciones entre individuos arraigados a un contexto particular y a una intención de sentirse parte de un colectivo. Sobre este último aspecto, reflexiona Giménez (2017) que entiende la identidad individual como la pertenencia a una comunidad. Esta implica compartir un núcleo de representaciones sociales en común, siendo características y definitorias.

En esta misma línea, la pertinencia del concepto de eficacia colectiva acuñado por el sociólogo Robert Sampson (2004) y sus consecuentes categorías analíticas, son de relevante pertinencia como aportación a la discusión descrita. Es evidente que las inquietudes intelectuales de este autor, se enfilan en tratar de darle al concepto de comunidad un contenido teórico orientado a la praxis. Su argumentación se basa en las acciones que realizan los individuos, dando génesis a la transición hacia colectivos caracterizados por trabajar en aras de objetivos comunes, como un efecto propio de contextos conflictivos.

Este último aspecto no es un tema menor, puesto que la eficacia colectiva se caracteriza por ser una reacción conjunta a problemáticas que aquejan a múltiples individuos, concordando en situaciones comunes. En el caso particular del autor, su producción académica dirige su análisis hacia los barrios, concretamente los ubicados en Chicago, Estados Unidos.

La eficacia colectiva se produce como una consecuencia con raíces multicausales. Las mismas, tienen una relación directa con lo que el noruego Johan Galtung (1998) denomina como violencia directa, estructural y cultural $^{9}$. La primera causa, hace referencia a la desigualdad social, expresada principalmente en segregación racial y desigualdad socioeconómica. La segunda, alude a problemáticas sociales ligadas a la seguridad como lo son la delincuencia juvenil, los conflictos vecinales, el ausentismo escolar y el maltrato infantil. La tercera, es denominada como factores de riesgo en niños y adolescentes, materializada en situaciones tales como familias monoparentales, contextos socioeconómicos pobres y el aislamiento racial. Finalmente, introduce el concepto de diferenciación ecológica con el objetivo de vislumbrar las fragmentaciones que se generan dentro de los mismos barrios por motivos de raza, clase social y salud. Concretamente, se enfoca en revisar la estratificación social que se genera al interior de las comunidades.

Teniendo presente la complejidad de las categorías esbozadas, la eficacia colectiva se configura como un accionar que estimula la cohesión y la confianza social con el ánimo de contribuir al buen vivir. Sampson (2004) la define de la siguiente manera:

El concepto de eficacia colectiva de los barrios captura el vínculo entre cohesión -especialmente confianza en la colaboración conjunta (working trust)y expectativas compartidas de acción. De la misma manera que la eficacia personal es un concepto situacional

9 La violencia directa hace alusión a la guerra y a los actos que atentan contra la vida y la integridad de seres humanos. La violencia estructural es aquella intrínseca al sistema político, social y económico, generando condiciones de explotación, fragmentación, penetración, segmentación y desestructuración (violencia contra las instituciones y procesos). Finamente, la violencia cultural se manifiesta en el patriarcado y la discriminación por múltiples factores: raza, nacionalidad, género, edad, convicciones políticas, etc. Para ampliar esta explicación a la propuesta de Galtung, se recomienda la lectura de Galaviz (2014). 
(uno tiene eficacia en relación a una tarea determinada), la eficacia de un barrio existe en relación con tareas concretas, como la de mantener el orden. El mecanismo causal clave en la teoría de la eficacia colectiva es el control social que se desarrolla en condiciones de confianza social (p. 238).

Ahora bien, es necesario aclarar que las causas nominadas, no son en sí mismas, las generadoras de eficacia colectiva. En el andamiaje explicativo de Sampson, es evidente que hay unos vecindarios concretos orientados a producirla, dado el cumplimiento de ciertas condiciones. Estos son la infraestructura institucional y la creación de confianza en la colaboración conjunta (working trust).

Acciones simples como la recolección de basuras, la elección para la ubicación de una estación de bomberos o la creación de escuelas, entre otras, dejan en evidencia que el contexto está situando sistemáticamente nuevos retos que no pueden ser resueltos de manera individual. La capacidad que tengan las comunidades para afrontar los desafíos de la cotidianidad, son básicos a la hora de construir confianza y redes de cooperación idóneos para fortalecer la capacidad de acción ante situaciones más complejas, como lo son las cuatro categorías causales.

Adicionalmente, el valor de la información es trascendental. Sampson (2004) introduce el concepto de gobernanza de los barrios, como la capacidad para autorregularse. La misma, debe estar soportada por la transparencia y visibilidad de la información por parte de las entidades estatales, mostrándoles a los vecindarios sus deficiencias, sus cifras y sus contextos de forma pública. En este estado de cosas, es de gran valía para los barrios conocer sus "puntos calientes ecológicamente problemáticos", con el objetivo de orientar la movilización comunitaria $^{10}$.

Otro concepto que trae a colación es el de símbolos visibles de desorden público, entendiéndolo como la capacidad y relevancia del papel ciudadano en el control del delito. En un contexto donde las tasas de delincuencia son altas, el ciudadano es el encargado de solicitar la presencia de la policía, actuando como informante natural. De esta manera, el accionar policial no está determinado por su presencia frecuente en los escenarios barriales conflictivos, sino como respuesta a un llamado en una relación de cooperación.

Sin embargo, en los contextos que son estudiados por Sampson (escenarios marcados por una fuerte discriminación racial), la percepción de la policía es de desconfianza e inutilidad. Por esta razón, se forman las policías comunitarias. Las mismas son entendidas como la organización conformada con el fin de sustituir algunos roles policiales como lo son el control de la seguridad, implicando de manera mucho más directa la responsabilidad de los vecinos con la seguridad colectiva y la resolución de conflictos.

Las policías comunitarias no pueden generar castigos a infractores de acuerdo a la ley, dado que no representan el monopolio de la fuerza y la justicia del Estado, como si lo representa la policía tradicional. Aun así, generan diferentes estrategias encargadas de regular el orden dentro de un margen de

10 Este concepto hace referencia, en la explicación de Sampson (2004), sobre las acciones proactivas de los vecindarios en lugares que generan delincuencia de forma desproporcionada. Las intervenciones estratégicas en ciertos nichos, propenden de manera eficiente a la mitigación de la violencia y su respectiva difusión espacial (p. 240). 
legalidad. Este hecho es uno de los más interesantes dentro de los estudios de eficacia colectiva, puesto que permite el análisis de la creatividad colectiva, los liderazgos, los lazos de cohesión encaminados al control y la convivencia pacífica.

Finalmente, con la suma de todos estos elementos, variando en formas, intensidades y órdenes según la particularidad de cada contexto, se genera lo que Sampson denomina como la "construcción de comunidad". Para este autor, la comunidad es "la capacidad que tiene un colectivo para dar respuestas sociales a problemas sociales" (2004, p. 244). Se hace un fuerte hincapié en la importancia de la eficacia colectiva como un insumo orientador del diseño e implementación de políticas públicas mejor construidas, dadas las aportaciones de los propios actores que demandan dichos procederes. No obstante, la eficacia colectiva es inútil resolviendo problemas estructurales, puesto que estos son obligación directa y primigenia del Estado.

Con estos insumos abordados, se utiliza como categoría complementaria, para el presente trabajo, la propuesta de resiliencia comunitaria de Munist et al. (1998). La misma es definida por estos autores como: "la capacidad de una persona o grupo social de enfrentar adecuadamente las dificultades, de una forma socialmente aceptable" (Alcaldía de Santiago de Cali, 2007, p. 7).

Dicha capacidad es alimentada con cuatro categorías que serán puestas en relación con la recaudación de la evidencia empírica, estas son: a) autoestima colectiva, entendida como el sentido de pertenencia hacia la comunidad, materializada en el orgullo que inspira la belleza física del contexto en términos ambientales o los valores distintivos que la comunidad profesa, b) humor social, como la capacidad del grupo para encontrar comedia en sus propias tragedias, c) honestidad estatal, entendida como la condenación y no reproducción de actos de corrupción por parte de funcionarios públi$\cos \mathrm{y}, \mathrm{d})$ identidad colectiva, abordada como la persistencia del ser social en su unidad y mismidad a través de cambios y circunstancias diversas que le permite afrontar la interculturidad (Alcaldía de Santiago de Cali, 2007). La Figura 2 sintetiza los principales insumos descritos de forma teórica.

Por su parte, el arquitecto Oscar Newman formula la que será la teoría complementaria de la investigación: los espacios defendibles. Esta construcción se gesta a principios de los años setenta del siglo pasado, generando una relación directa entre el diseño de las casas y los vecindarios con la seguridad de los habitantes. Para este autor, los problemas de seguridad de los contextos periféricos, marginados social y económicamente, obedecen a un problema de corte arquitectónico que está siendo resuelto a través de la implementación de una política pública ineficaz. Es decir, el incremento de policías y personal representante del monopolio de la fuerza del Estado.

$\mathrm{Su}$ ineficacia se basa en la densidad territorial, puesto que los contextos mencionados cada vez son más amplios en cuanto a espacio y población. En este orden de ideas, el espacio defendible puede entenderse como la configuración de un entorno residencial con unas características físicas funcionales a los habitantes, dotándolos de la capacidad de gestionar su propia seguridad (Rao, 2016).

Newman (1972) enfoca su análisis en la ciudad de Nueva York, encontrando algunos 


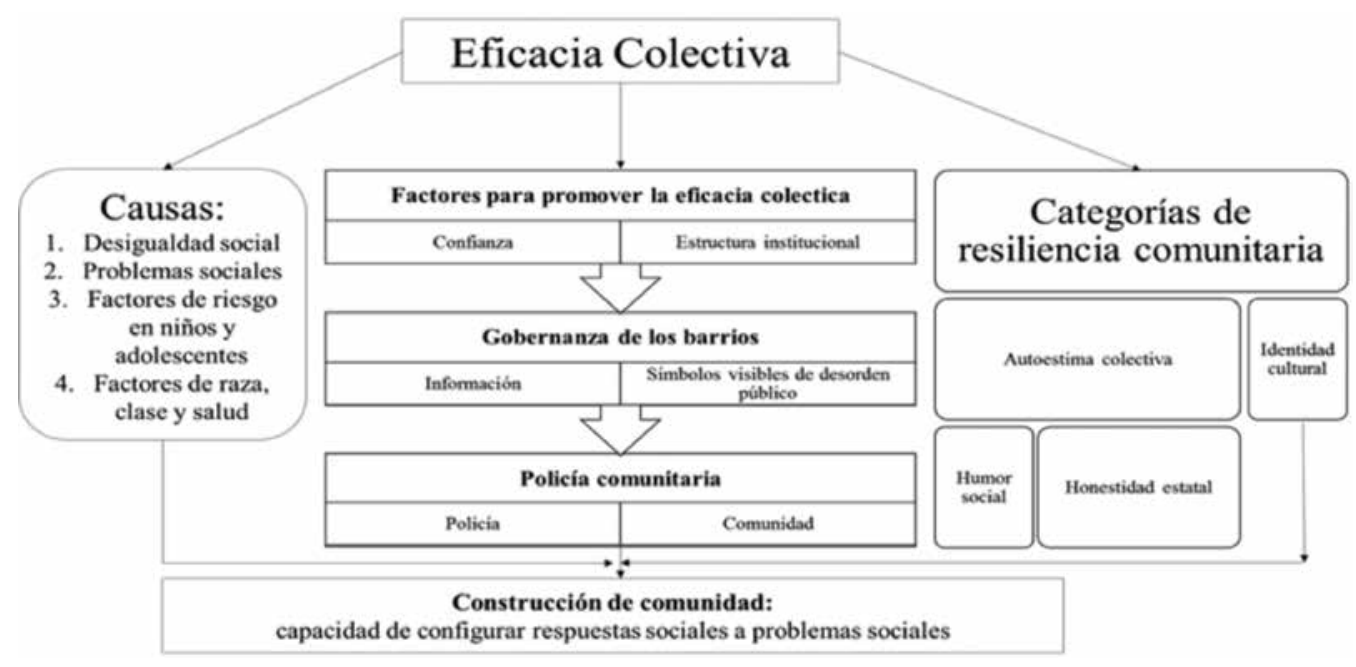

Figura 2. Proceso de eficacia colectiva

Fuente: Sampson, 2004; Alcaldía de Santiago de Cali, 2007. Elaboración propia.

factores de inseguridad asociados al diseño de los proyectos de vivienda. Por ejemplo, menciona que son emprendimientos muy grandes, acomodando a veces más de 1000 familias en un mismo espacio. Son torres residenciales de más de 7 pisos. Los sitios son ensamblajes de lo que antes eran cuatro o seis cuadrantes urbanos (varios barrios), formados por "supercuadras" cerradas al tráfico.

Posterior al esbozo de esta crítica, su argumentación se enfila hacia la modificación de ciertos espacios problemáticos con el fin de acondicionarlos como espacios más seguros. Menciona como botones de muestra, el uso de cercas y elementos simbólicos para prevenir el robo; mostrando como resultado disminuciones del $80 \%$ de estas actividades en esa zona específica. Adicionalmente, los espacios pueden adecuarse de acuerdo a la necesidad concreta de la comunidad y con esto garantizar escenarios más amenos. Por ejemplo, dice que al jugar los niños pequeños generalmente a la entrada de los edificios, lo que debe hacerse es colocar bancas y zonas de juegos en estos espacios, configurándolos como puntos focales donde la comunidad haga mayor presencia, siendo capaz de estar pendiente de la seguridad individual y colectiva, logrando así estimular la vigilancia natural, puesto que los hurtos generalmente se ejecutan en zonas semipúblicas. Para efectos de este trabajo, solo se tendrá en cuenta la esencia de esta teoría, pues se debe reconocer que el diseño arquitectónico de la Nueva York de los setenta, dista bastante de las características físicas del BMFS.

\section{ESTADO DE LA CUESTIÓN}

El trabajo de Valenzuela (2012) propone medir el concepto de eficacia colectiva en la ciudad de Cuernavaca, México, 
desarrollando 520 encuestas en las cuales se miden las variables: control social del espacio, vulnerabilidad de los habitantes, acciones en pro de la eficacia colectiva, legalidad y sentimientos de inseguridad. Como rasgo común con la presente investigación, se tienen en cuenta elementos ligados al sentido de pertenencia de los cuernavaquenses a las distintas colonias que compone la ciudad y la construcción de asociaciones vecinales. También, se rescata el trabajo de Fernández-Toribio (2015); su investigación, adscrita al campo de la criminología en Barcelona, concluye que el papel de actores clave dentro de las comunidades (en el caso de su investigación, los comerciantes) y el uso de herramientas de tecnologías de la información y la comunicación, como WhatsApp, son de gran valía para ampliar la eficacia colectiva de la ciudad analizada.

Por otro lado, desde el campo de la educación y la pedagogía, se observaron dos estudios de interés. El primero es el de López-Alfaro et al. (2016), donde se desarrolla un estudio correlacional entre la distribución y profesionalización del liderazgo de 587 docentes bogotanos en conjunción con los conceptos de eficacia colectiva y expectativas. El segundo es el de Pérez et al. (2012), en el cual se comprueba la relación inversamente proporcional entre eficacia colectiva e inseguridad (comprobando lo postulado por Sampson), donde al subir la primera, disminuye la segunda. Esta investigación se desarrolló evaluando la percepción de inseguridad de 4000 estudiantes de carreras universitarias del Servicio Nacional de Aprendizaje (en adelante SENA) en Colombia.

Por otro lado, desde los estudios de los asuntos públicos y la sicología educativa, se remiten los trabajos de Olavarría Gambi et al. (2008) y Ruiz Pérez (2015). En el primero, a través de la medición de las categorías control social, cohesión social, vigilancia informal o tutela y monitoreo de grupos adolescentes, se pretende nutrir de base empírica la construcción de políticas públicas capaces de hacer frente al delito y la inseguridad en Chile, valiéndose de la propuesta teórica de Sampson. En el segundo, se trabajan de manera mancomunada los conceptos de eficacia colectiva y resiliencia comunitaria, a través de una muestra no aleatoria de estudiantes de distintos niveles educativos, comprobando la fiabilidad interna de la escala RC construida por el autor.

Respecto al estado de la cuestión, de literatura reciente, sobre aplicación empírica o discusión teórica sobre espacio defendible, destaca la ponencia de Molero (2014). Este autor, se encarga de hacer una breve revisión documental donde relaciona las variables seguridad, ciudadanía y convivencia. Utiliza algunas categorías de la teoría de Newman con el objetivo de argumentar la importancia del estímulo de la vigilancia natural por parte de entidades públicas encargadas de la seguridad. Porretta (2010) por su parte, reflexionando sobre la ciudad de Barcelona, enlistando los argumentos de Newman como estrategias utilizadas en el diseño arquitectónico de ciudades más seguras, producto de una discusión sobre lo que denomina "ciudades del miedo", analizando bajo este concepto su estudio de caso.

Anguiano (2016), realiza un estudio similar al esbozado en este documento. Valiéndose de las premisas básicas de la teoría del espacio defendible de Newman, acompañado de categorías propuestas por autores que complementaron la teoría con aproximaciones empíricas (Coleman, Jacobs, Greenberg, 
Rohe y Williams), trata de responder a la pregunta: ¿Por qué la ciudad de Colima es una de las más seguras de México? Su artículo concluye que no hay una correlación fuerte entre características de urbanización y delito, haciendo posteriormente varias sugerencias de carácter arquitectónico para dirimir las posibilidades de reproducir hurtos en esta urbe. Finalmente, Gutiérrez Rivera (2017), en su tesis de especialización realiza un recorrido histórico en el cual se analizan los distintos cambios de corte urbanístico en Bogotá, focalizando su trabajo en la primera administración de Enrique Peñalosa, todo esto bajo articulaciones conceptuales de la teoría del espacio defendible.

Así, se evidencia una combinación de metodologías cualitativas y cuantitativas donde predominan las aproximaciones de carácter deductivo posteriores al esbozo de categorías de las teorías de Sampson y Newman. Sin duda, los investigadores hispanos consultados abordaron situaciones muy disímiles, demostrando así, que la teoría de la eficacia colectiva posee un largo alcance, acompañado de un alto valor explicativo. En el caso de la teoría del espacio defendible, prima la aproximación empírica a ciudades en su conjunto, haciendo estudios locales amplios.

\section{Metodología}

Cómo se adelantó en la introducción, el trabajo se desarrolló en dos fases: la primera fue de contextualización y observación pasiva. Es decir, se indagó sobre las características físicas del BMFS revisando sus datos demográficos, su ubicación dentro de la ciudad de Cali, las características de los barrios colindantes y su estrato socioeconómico.
Posteriormente, se utilizó la observación pasiva entendida como la recaudación de datos empíricos sin que los actores observados participen activamente (Fernández-Toribio, 2015), con el objetivo de ubicar los enrejados respectivos y entender su funcionamiento.

La segunda etapa fue la de entrevistas semiestructuradas a los líderes barriales Amparo Navarro y Freddy Norato. Corbetta (citado por Fernández-Toribio, 2015, p. 23) define la entrevista cualitativa como: "la conversación provocada por el entrevistador, realizada a sujetos seleccionados a partir de un plan de investigación, con la finalidad de conocer la perspectiva del sujeto, de comprender sus categorías mentales, sus interpretaciones y percepciones".

Concretamente, la entrevista semiestructurada (también denominada como mixta) tiene como característica la flexibilidad en la formulación de los interrogantes, alternando preguntas preparadas con preguntas espontáneas. Se entrevistó a los dos líderes comunales de forma conjunta con el objetivo de indagar acerca de los motivos que dieron origen a la instalación de los enrejados, el funcionamiento de los mismos y las acciones que emprende la comunidad para incentivar la cohesión, entre otros insumos de relevancia.

Culminado este emprendimiento, se procedió a entrevistar a la líder comunal Edilma Muñoz del barrio Antonio Nariño (en adelante BAN), con el objetivo de analizar en perspectiva comparada las acciones de un barrio seguro en contraste con uno de los más peligrosos de la ciudad, para así determinar posteriormente, la eficacia colectiva de las acciones emprendidas en cada contexto. 


\section{Resultados}

\section{Fase 1. El acercamiento}

El BMFS se encuentra ubicado en la comuna 4 de la ciudad y tiene un promedio ponderado en un aproximado de 1356 habitantes. Dicha comuna se encuentra ubicada al noreste de la ciudad. Del total reseñado, la cantidad predominante de población oscila entre los 5 y 14 años (256 personas que representan el $18.9 \%$ del total de habitantes). Los barrios limítrofes son: Evaristo García, Popular, Guillermo Valencia y La Isla. Su estrato socioeconómico es el 2, en una escala de 0 a 5 (Alcaldía de Santiago de Cali, 2017). En la Figura 3 se muestra su ubicación de forma gráfica.
Como se mencionó anteriormente, la observación se realizó tratando de conocer a fondo el contexto geográfico del BMFS. El proceso que se ejecutó fue el de recorrer el barrio a plenitud en un total de 5 visitas, que se distribuyeron en horas de la mañana y la noche, esto con el objetivo de tratar de comprender su funcionamiento en las distintas temporalidades del día.

Lo que se pudo determinar como rasgo característico del barrio, es que este posee una forma cuadriculada, materializada en cinco cuadras de manera vertical y cinco de manera horizontal ${ }^{11}$. En el proceso de observa-

11 Para efectos de la investigación, se tomará la definición de cuadra de la RAE, entendida como: "En una calle, espacio comprendido entre las dos esquinas de un lado de una manzana" (Real Academia Española, 2017).

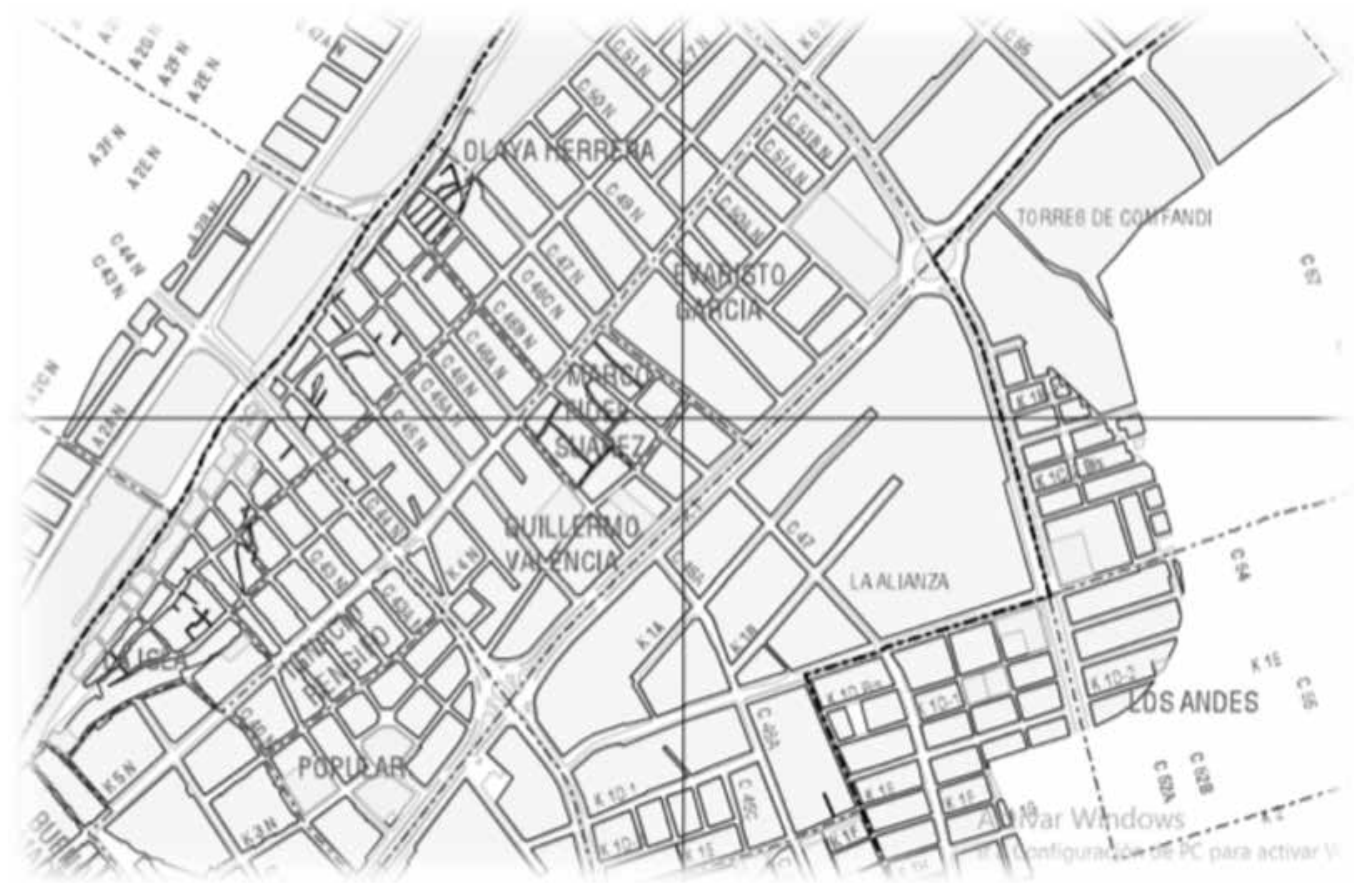

Figura 3. Ubicación del barrio Marco Fidel Suárez. Comuna 4. Cali, Colombia

Fuente: Alcaldía de Santiago de Cali, sin fecha (s. f.). 


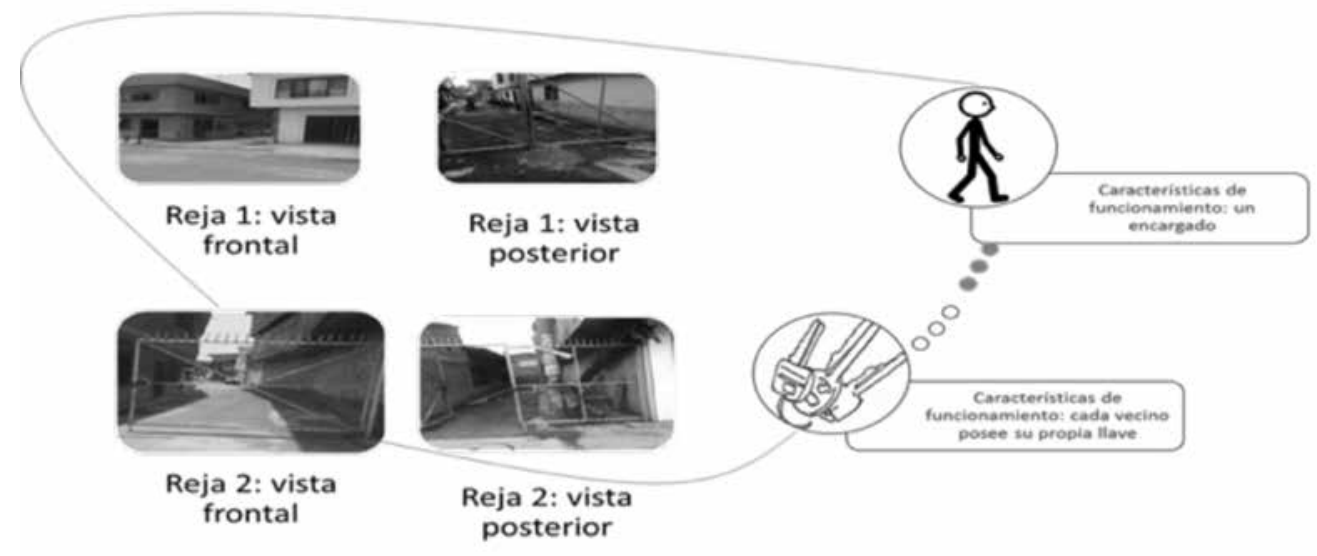

Figura 4. Rejas 1 y 2. Barrio Marco Fidel Suárez. Cali, Colombia

Fuente: toma y elaboración propia.

ción, se registraron cuatro enrejados sobre dos cuadras, los cuales estaban abiertos hasta las 9:00 p. m. Posteriormente fueron cerrados, pero cada uno funcionaba de manera distinta: el primero (que se denominará reja 1) fue cerrado por una de las vecinas residentes mientras que el segundo reproduce este mismo proceso por distintos habitantes de la cuadra enrejada. La particularidad radica en que esta es abierta de manera constante; lo que se observó, fue que cada habitante posee su propia llave. De esta manera, se logró comprender que el funcionamiento de ambos enrejados es independiente. En el primero, la regulación es ejercida directamente por una persona encargada; mientras que en el segundo, cada vecino residente debe poseer su propia llave. En la Figura 4 se retrata el sistema de seguridad reseñado.

\section{Fase 2. Conociendo el contexto desde la voz de sus líderes}

En entrevista con los líderes comunales, se manifestó que la idea de las rejas surgió de un argumento enfocado en la ubicación. El hecho de estar situados en la comuna $4 \mathrm{y}$ que esta sea un sector industrial tradicional de Cali, hacía que principalmente mujeres trabajadoras de industrias aledañas al BMFS tuvieran la obligatoria necesidad de transitar por las dos cuadras más inseguras del sector. Esta situación generaba atracos reiterados perpetrados por personas ajenas al barrio. Como valor agregado, al malestar propio de la inseguridad de los atracos, se sumó un acontecimiento que marcó la historia del barrio: un intercambio de disparos donde fallecieron algunos habitantes de la comunidad y otros ajenos.

Derivado de este hecho, el proceso de instalación de los enrejados se realizó de manera mancomunada entre la JAC y la comunidad. El Gobierno municipal no ofreció ninguna ayuda, pues argumentaba que en cuadras cercanas al puesto de salud, estas se encargarían de obstaculizar el paso en caso de urgencias, por lo tanto no lo veían como un 
accionar oportuno. Aun así, se recogieron los recursos económicos necesarios a través de ventas de comida (o lo que los entrevistados denominan como quermeses), sumado a aportes voluntarios de algunos vecinos residentes. De esta manera se instaló la primera reja hace aproximadamente 20 años.

Es perentorio afirmar, que el principal motivo por el cual se instalaron los enrejados, fue por la acumulación de personas consumidoras de drogas en dos de sus cuadras, identificando así lo que Sampson denomina "puntos calientes ecológicamente problemáticos". Otro aspecto importante a destacar, es la percepción de seguridad que los líderes manifiestan. Según sus afirmaciones, después de la instalación de los enrejados, ya no hay 'mariguaneros'. Además, se fortalecieron los lazos de solidaridad, puesto que: "no creen, ni sienten, que alguno de sus vecinos (residentes en las cuadras enrejadas) pueda generar algún daño a la comunidad"12.

Sin duda, la percepción de cambio positivo es evidente. Para ellos se generó una transición de "una guerra del Oeste" a habitar uno de los barrios más seguros de la comuna. La presidenta de la JAC, Amparo Navarro, manifestó que en el 2012 solo hubo un homicidio, arguyendo: "con hechos se comprueba que las rejas sí sirven".

Recogiendo todo lo anterior, es menester rescatar la ferviente intención de los líderes comunales como representantes de su comunidad, de interpretar el encerramiento voluntario como una herramienta eficaz para la preservación de la seguridad. En palabras de los líderes, se manifiesta la

12 Las palabras en cursivas y entre comillas son expresiones literales pronunciadas por los entrevistados. A lo largo del apartado se hará uso de este recurso en páginas posteriores. intención de generar una urbanización de tipo conjunto residencial dentro del contexto en el que viven. Su comentario fue el siguiente: "Nuestra idea es que nuestro barrio parezca una ciudadela, así como Chiminangos ${ }^{13}$, son barrios pero encerrados, cada uno con su llave"; es decir, que articulada a esta idea, está la de los conjuntos residenciales como modelo y símbolo de seguridad.

Como valor agregado, aparte de la solicitud de reseña sobre los motivos por los cuales se instalaron las rejas 1 y 2 , se indagó por actividades que rebasen esta estrategia de seguridad encaminadas a la construcción de comunidad en sintonía con la definición de Sampson. De esta manera, se orientó la discusión hacia tres aspectos clave: problemas del barrio, soluciones propuestas y actividades para fortalecimiento de la convivencia. Lo dicho se postula partiendo de un principio lógico: los enrejados en sí mismos no mantienen un barrio unido $\mathrm{y}$ seguro, es necesario el desarrollo de acciones colectivas aledañas que fortalezcan este emprendimiento. De esta manera, producto de la información recaudada se desprende la Tabla 1.

Por otro lado, se realizó una entrevista con Edilma Muñoz, conciliadora del BAN, con el objetivo de contrastar las respuestas de la comunera de uno de los barrios más peligrosos de Cali en parangón con el barrio objeto de estudio. El formato de entrevista sobre el cual se desarrollaron las preguntas fue idéntico al que se utilizó con los líderes del BMFS.

De esta manera, se sostuvo por la entrevistada que el problema eje del BAN es la

13 Barrio cercano, constituido por múltiples edificios residenciales. 
Tabla 1. Problemas, soluciones y actividades para fortalecer la convivencia del barrio Marco Fidel Suárez

\begin{tabular}{lll}
\hline \multicolumn{1}{c}{$\begin{array}{c}\text { Problemas descritos por } \\
\text { los líderes }\end{array}$} & \multicolumn{1}{c}{ Soluciones } & \multicolumn{1}{c}{$\begin{array}{c}\text { Actividades para fortalecer la } \\
\text { convivencia }\end{array}$} \\
\hline -Seguridad: expendio y & -Convenios educativos con el & \multicolumn{1}{c}{-Entrega de juguetes a los niños de esca- } \\
consumo de drogas - hurto & SENA en programas técnicos \\
callejero. & $\begin{array}{l}\text { sos recursos del barrio. Esta actividad es } \\
\text { financiada por los dueños de tiendas y }\end{array}$ \\
-Desempleo: a pesar de ser la capacitación y & "ocupar la mente de jóvenes que co- & pequeños negocios de la comunidad. \\
un sector industrializado, & rren el riesgo de caer en la droga". & -Actividades recreativas: salidas a cine y \\
no existe una alta emplea- & & a sitios turísticos dentro de la ciudad. \\
bilidad de los habitantes & -Jornadas de salud, odontología y pelu- \\
del barrio. & quería, asesoría jurídica. Dicha actividad \\
& se desarrolla con recursos del municipio \\
& gestionados por la JAC. \\
& -Celebración del aniversario del barrio, \\
& fechas especiales: días del padre y de la \\
& madre. \\
& -Servicio de guardería en la casa de \\
& juntas de la JAC. \\
\hline
\end{tabular}

Fuente: elaboración propia a partir del testimonio de los entrevistados.

"inseguridad y la descomposición social"14, pues abundan familias disfuncionales en donde se carece de la figura del padre o de la madre, "los niños prácticamente se cuidan solos pues viven en el encierro en sus casas sin ningún control ni orientación". Otro aspecto presente son los conflictos violentos, las disputas entre niños y una cultura de enemistad en donde el individualismo es el principal determinante de la conducta.

Esta agresividad en el comportamiento, está supeditada a la pobreza como causal de un estrés propio de las carencias básicas generadas por la ausencia de empleo. Otro asunto que opera como desencadenante de malestar, es la gran extensión territorial que

14 Este último concepto utilizado por la entrevistada es ampliado por Ruíz Perales (2014) de la siguiente manera: "La descomposición social es el resultado de varios factores que influyen en la misma población a través del tiempo; es decir, comparando lo que acontece actualmente con hace aproximadamente 20 años los niveles de contaminación, desempleo, poder adquisitivo, violencia, inflación, corrupción, degradación de los valores humanos, consumismo, drogadicción, etc., son mayores". lo sitúa como más difícil de controlar. Como complemento, existen litigios entre pandillas del mismo barrio por factores ligados al territorio, materializados en la instauración de fronteras invisibles.

De las pocas soluciones a este problema diseñado e implementado por administraciones anteriores, se ubica en un primer momento el ofrecimiento a los jóvenes en situaciones de vulnerabilidad la posibilidad de ser vigilantes del barrio, pagados por los mismos vecinos. Este programa en la actualidad solo tiene unos pocos integrantes, y según la entrevistada parafraseando a algunos de sus vecinos, se afirma que se han convertido en ladrones que cobran para no robar, pues si los vecinos se rehúsan a pagar, ellos mismos se encargan de despojarlos de las pertenencias que dicen cuidar. La segunda iniciativa es el aprovechamiento del terreno: por iniciativa propia de algunos jóvenes con ánimo de rehabilitarse, se crearon escenarios parecidos 
a granjas donde se crían animales y se cultivan algunas hortalizas y verduras.

Un asunto que se escuchó de manera reiterada durante la entrevista fue la siguiente suma de factores: poca comunicación, carencia de diálogos, poca diligencia y fragmentación de la JAC, teniendo un papel más simbólico que operativo. Se escuchan entre los vecinos frases como "la junta (JAC) no hace nada" y "las calles están destapadas y no hay ninguna gestión", haciendo alusión al mal estado de las vías que conforman el barrio.

Para entender estas realidades, es necesario tener claro que las comunidades son grupos de personas que habitan un mismo territorio, comparten costumbres, creencias y valores, desarrollan lazos de amistad y solidaridad, tienen necesidades e intereses comunes, realizan una permanente interacción social y buscan con su acción colectiva, mejorar sus condiciones materiales y espirituales de vida. Los líderes son aquellas personas a la cabeza de estos colectivos, impulsando y guiando su accionar.
Por lo tanto, el liderazgo transformador, concepto utilizado por Montero (2006), sería todos aquellos vínculos en donde el líder a la cabeza logra generar una relación recíproca con la comunidad estableciendo nexos afectivos, los cuales están marcados por la solidez de objetivos comunes entre el conjunto y el individuo que dirige, en últimas debe existir una relación legítima. Al respecto afirma:

Los líderes transformadores desarrollan sólidos vínculos con los demás miembros de la comunidad, quienes a su vez le corresponden con intensa simpatía y cariño, presentes aún en aquellas personas menos participativas que ayudan desde lejos, que dan su aprobación, pero no mucho más, o que se involucran esporádicamente en las actividades comunitarias (p. 98).

A continuación se introducirán las características del líder transformador a la realidad de los barrios BMFS y BAN para lograr comparar sus discrepancias.

Tabla 2. Liderazgos comparados: barrios Marco Fidel Suárez y Antonio Nariño

\begin{tabular}{|c|c|c|}
\hline Características del líder transformador & $\begin{array}{l}\text { Realidad del barrio } \\
\text { Marco Fidel Suárez }\end{array}$ & $\begin{array}{c}\text { Realidad del barrio } \\
\text { Antonio Nariño }\end{array}$ \\
\hline $\begin{array}{l}\text { Los líderes son motivadores. Movilizan e } \\
\text { inducen a otros miembros de la comuni- } \\
\text { dad a llevar a cabo o contribuir con mayor } \\
\text { intensidad o alcance del que habían pro- } \\
\text { metido originalmente o del que se esperaba } \\
\text { de ellos. }\end{array}$ & $\begin{array}{l}\text { Las últimas actividades desarro- } \\
\text { lladas dentro del barrio, han sido } \\
\text { desarrolladas y ejecutadas por } \\
\text { la JAC de la mano de Amparo } \\
\text { Navarro y Freddy Norato. }\end{array}$ & $\begin{array}{l}\text { No hay actividades ni } \\
\text { inducción de la comu- } \\
\text { nidad a la instauración } \\
\text { de objetivos comunes. }\end{array}$ \\
\hline $\begin{array}{l}\text { Tratan de fomentar y aumentar la partici- } \\
\text { pación de las personas tímidas o apartadas. } \\
\text { En general, procuran incorporar nuevos } \\
\text { miembros tanto a los grupos organizados } \\
\text { como a las actividades emprendidas desde } \\
\text { ellos, comprometiendo al mayor número } \\
\text { de personas posible en diferentes tareas, } \\
\text { distribuyendo así el esfuerzo y generando } \\
\text { más compromiso. }\end{array}$ & $\begin{array}{l}\text { Las actividades desarrolladas } \\
\text { siempre son hechas por y para } \\
\text { la comunidad; ejemplo de ese } \\
\text { fomento a la participación se } \\
\text { evidencia en la entrega de regalos } \\
\text { en el mes de diciembre, pues } \\
\text { en colaboración con la JAC, se } \\
\text { articuló la presencia de tenderos y } \\
\text { dueños de negocios del barrio. }\end{array}$ & $\begin{array}{l}\text { No existe un fomento a } \\
\text { la participación interna } \\
\text { dentro de la misma } \\
\text { JAC. }\end{array}$ \\
\hline
\end{tabular}




\begin{tabular}{|c|c|c|}
\hline Características del líder transformador & $\begin{array}{l}\text { Realidad del barrio } \\
\text { Marco Fidel Suárez }\end{array}$ & $\begin{array}{l}\text { Realidad del barrio } \\
\text { Antonio Nariño }\end{array}$ \\
\hline $\begin{array}{l}\text { Colocan el beneficio de la comunidad y de } \\
\text { sus grupos organizados por encima del } \\
\text { interés propio, estimulando el desarrollo } \\
\text { de la comunidad. }\end{array}$ & $\begin{array}{l}\text { Hay una gran inversión de tiem- } \\
\text { po y recursos propios a las activi- } \\
\text { dades diseñadas y desarrolladas. }\end{array}$ & $\begin{array}{l}\text { El individualismo es } \\
\text { determinante de la } \\
\text { mayoría de las interac- } \\
\text { ciones sociales. }\end{array}$ \\
\hline $\begin{array}{l}\text { Tratan de que la participación en activi- } \\
\text { dades para alcanzar metas comunitarias } \\
\text { tenga efectos compensatorios para quienes } \\
\text { participan en ellas. Fomentan la alegría y el } \\
\text { goce en la tarea. }\end{array}$ & $\begin{array}{l}\text { La actividad en que se conme- } \\
\text { morará el aniversario del barrio, } \\
\text { el día del padre y de la madre, } \\
\text { es una actividad en la cual se } \\
\text { pretende dar un reconocimiento a } \\
\text { los tenderos que participaron en } \\
\text { la entrega de regalos del mes de } \\
\text { diciembre. }\end{array}$ & $\begin{array}{l}\text { No hay actividades } \\
\text { en las cuales se pueda } \\
\text { compensar. }\end{array}$ \\
\hline $\begin{array}{l}\text { Procuran estimular intelectualmente a sus } \\
\text { compañeros de actividades y a otras perso- } \\
\text { nas de la comunidad. Buscan el desarrollo } \\
\text { personal de los participantes. }\end{array}$ & $\begin{array}{l}\text { Se ha insertado a varios jóvenes } \\
\text { en el SENA para estudiar carreras } \\
\text { técnicas. }\end{array}$ & $\begin{array}{l}\text { Se han tratado de } \\
\text { generar alianzas con } \\
\text { la Policía para brindar } \\
\text { capacitaciones de } \\
\text { vigilancia, pero esta } \\
\text { intención no ha tenido } \\
\text { mucho éxito. }\end{array}$ \\
\hline
\end{tabular}

Fuente: elaboración propia, de acuerdo a lo formulado por Montero (2006) y entrevistas.

Es importante evaluar a esta altura el cumplimiento de ciertas categorías de la teoría de resiliencia comunitaria descrita en el apartado teórico. Por ejemplo, en la categoría de autoestima colectiva entendida como el sentido de pertenencia hacia el contexto en el que se vive, se genera como vínculo el uso de frases tales como: "somos el barrio más seguro de Cali", o "tenemos la camiseta puesta", utilizada por la entrevistada Amparo Navarro. Acciones adicionales descritas en las entrevistas, como pintar la casa comunal (espacio oficial donde se desarrollan las reuniones comunales) y el apoyo a la banda marcial del barrio (colectivo musical), son todos elementos que delatan el sentido de pertenencia de los habitantes hacia su comunidad. Otros insumos son las jornadas de salud para beneficio de los vecinos. Categorías como la identidad cultural y humor social son materializadas con las actividades anteriormente descritas.

\section{Discusión}

Maldonado y Rincón (2007, p. 114) definen los espacios residenciales multifamiliares como una forma particular de vivienda de acceso controlado, integradas arquitectónica y funcionalmente. En un estudio realizado por ellas con recursos de la Facultad de Humanidades de la Universidad del Valle, donde se entrevista a 44 personas acerca de los motivos por los cuales habitan conjuntos residenciales en la ciudad de Cali, circulan múltiples respuestas donde el factor seguridad es hegemónico. Expresiones como: "son sitios más tranquilos", "aquí estamos alejados de los hurtos de barrios vecinos" o "lo bueno de estar aquí es que estamos 
encerrados, hay vigilancia", son argumentos donde se evidencia una legitimación hacia el encerramiento voluntario como opción de seguridad ${ }^{15}$.

Para estas trabajadoras sociales, los conjuntos residenciales son ciudades al interior de una ciudad que se constituyen bajo un justificante que es ambiguo y polisémico. La seguridad en términos básicos es concebida como ausencia de hurtos, aunque en su interior se construye en el marco de imaginarios "ligados a calidad de vida, la resolución de problemas domésticos (cuidado de menores, adultos mayores y enfermos), el aumento del patrimonio y el aporte de prestigio" (Maldonado y Rincón, 2007, p. 135).

En el caso del BMFS, no se evidencia una aproximación directa a conjuntos residenciales en los cuales se encierre por completo la totalidad de las calles, generando una apariencia uniforme donde todas las viviendas poseen un aspecto similar (o igual), dando especial relevancia a la vigilancia privada y a costes de mantenimiento que recaen sobre un administrador, tal y como se hace en los conjuntos residenciales clásicos. Lo que se deduce de este escenario, es un proceso de emulación en el cual se utiliza esta estrategia en los puntos problemáticos de la comunidad, con el objetivo de favorecer un control que recae sobre las manos de los propios habitantes.

15 Los criterios sobre los cuales se analizaron estas entrevistas fueron bajo un parámetro de análisis de las respuestas ofrecidas categorizándolas entre estrato socioeconómico (medio-bajo) y sexo (hombre/mujer). Los resultados se organizaron de acuerdo a respuestas comunes donde se buscó la determinación de patrones en común para vislumbrar los motivos para vivir en conjuntos residenciales. Estos fueron: motivos económicos y de seguridad, cambios en el ciclo de vida familiar, ubicación al interior de la ciudad, tener un servicio privado de garantía de la seguridad (vigilancia privada) y servicios colectivos y resguardo a la seguridad de menores.
Por lo tanto, en este barrio se evidencia una nueva forma de espacio residencial multifamiliar, donde se conjuga la forma tradicional de vivienda con espacios modificados producto de la coyuntura generada por el contexto de la ciudad, los barrios aledaños y la creatividad de sus residentes. Sin duda, la influencia en el imaginario social del conjunto residencial como enclave de seguridad, prestigio y patrimonio, surgió como una alternativa a la búsqueda de estrategias de eficacia colectiva construidas por la comunidad.

El objetivo del BMFS no es vivir en un área encerrada que los diferencie de los demás barrios aledaños en un marco de estratificación popular. Más bien, es un medio para mejorar las condiciones de vida, construyendo ambientes más tranquilos y seguros para el desarrollo de la cotidianidad. En otras palabras, la emulación de espacios residenciales multifamiliares se apuntala como la estrategia particular de esta comunidad en específico, para consolidar su propio espacio defendible.

El situar enrejados, es una modificación del entorno, que tiene su génesis en la búsqueda y encuentro de espacios problemáticos-inseguros. En adición, la comunidad no percibe las rejas 1 y 2 como la solución intrínseca al problema, puesto que ha desarrollado estrategias de vigilancia natural que acompañan la maniobra convirtiéndola en proceso. Corroborando que no se puede ser determinista con el argumento arquitectónico, puesto que el diseño per se no garantiza seguridad en un $100 \%$. De esta manera, han adecuado su entorno a las necesidades propias del colectivo.

Por otro lado, con la evidencia empírica recaudada por las entrevistas y la observación 
pasiva, se hace innegable el uso de diferentes categorías de la teoría de la eficacia colectiva al servicio de la construcción de ambientes más seguros por parte de los residentes del BMFS. Elementos propios como la configuración de redes de comunicación e infraestructura institucional, el reconocimiento de puntos problemáticos que atentan contra el mantenimiento de la normalidad transitando hacia la aparición de conflictos que se resuelven de manera violenta, sumado a la identificación de símbolos visibles de desorden público, en donde la comunidad toma un rol de control policial a través de la cooperación o reemplazo de entidades estatales que juegan este rol, son de suma utilidad para comprender el proceso de eficacia colectiva donde el conjunto de habitantes resuelve socialmente lo que se constituía como un problema colectivo, generando así una transición del vecindario a la comunidad. A continuación la Tabla 3 amplía lo expresando en este párrafo.

Con base en lo esbozado, ¿se puede afirmar que existe un vínculo en la construcción de paz como campo investigativo y los estudios de eficacia colectiva? La respuesta aportada por este artículo sería un sí, con una necesaria matización. Se puede hablar de construcción de paz a través de accionares de eficacia colectiva si se analiza bajo un derrotero de paz imperfecta, es decir, de pequeñas o grandes acciones que reemplazan por acciones no violentas el uso de la violencia como mecanismo de resolución de conflictos. Lo que no es perentorio afirmar, es que se generen procesos de paz positiva,

Tabla 3. Eficacia colectiva en el barrio Marco Fidel Suárez

\begin{tabular}{ll}
\hline Categorías de eficacia colectiva & Realidad del barrio Marco Fidel Suárez \\
\hline $\begin{array}{l}\text { Causas: desigualdad social, proble- } \\
\text { mas sociales, factores de raza, clase } \\
\text { y salud, factores de riesgo en niños y } \\
\text { adolescentes. }\end{array}$ & $\begin{array}{l}\text { Inseguridad como problema social y factor de riesgo en niños } \\
\text { y adolescentes. }\end{array}$ \\
\hline Confianza y estructura institucional. & $\begin{array}{l}\text { Se evidencian en la construcción de las rejas y en las varias } \\
\text { acciones de carácter comunal que son promovidas por la JAC } \\
\text { y desarrolladas por la comunidad. }\end{array}$ \\
\hline $\begin{array}{l}\text { Reconocimiento de puntos calientes } \\
\text { ecológicamente problemáticos. }\end{array}$ & $\begin{array}{l}\text { La ubicación de las rejas uno y dos se sitúa sobre lugares } \\
\text { estratégicos que anteriormente eran escenarios de violencia } \\
\text { directa y hurtos callejeros. }\end{array}$ \\
\hline Símbolos visibles de desorden público. & $\begin{array}{l}\text { La comunidad se ha constituido como un actor con caracterís- } \\
\text { ticas policiales, en la medida en que ha configurado acciones } \\
\text { de hecho no violentas para controlar hurtos y muertes en } \\
\text { su territorio, a través de la regulación de la entrada y salida } \\
\text { de residentes del barrio. En adición, actúa en colaboración } \\
\text { con cuadrantes de la Policía ante situaciones que exigen el }\end{array}$ \\
$\begin{array}{l}\text { uso de la fuerza legítima del Estado. Al haber una relación } \\
\text { de cooperación, no se evidencia un deseo de reemplazar la } \\
\text { institucionalidad. }\end{array}$ \\
\hline
\end{tabular}

Construcción de comunidad en torno

a un proyecto común: la emulación de

espacios residenciales multifamiliares

Fuente: elaboración propia con insumos de Sampson (2004). 
puesto que acciones colectivas propias de la agencia, difícilmente resolverán un problema que es estructural y que se configura como competencia del Estado.

No obstante, la importancia que tiene para el investigador social analizar el detalle de espacios, discursos, comportamientos que aparentemente son cotidianos, es de suma importancia para estudiar los contextos en armonía con constructos teóricos que en un primer momento parecen de difícil aplicación a la realidad producto de su abstracción. Hablar de acciones colectivas que mejoren las condiciones de vida de un cúmulo de individualidades, lucen como gestos políticos anclados a discursos contrahegemónicos, donde los colectivos buscan influir las acciones del Estado, en otras palabras, los movimientos sociales. Sin embargo, estas organizaciones, tanto urbanas como rurales, se ven en la necesidad de construir vínculos que rebasen la convivencia para resolver las disyuntivas que el contexto presenta. Estas acciones pueden limitarse a alterar la apariencia del entorno y adoptar roles simbólicos que cambian por completo la forma de vida de la gente.

Sin duda, aproximaciones bajo este enfoque pueden ser de utilidad para analizar o construir programas de política pública que estimulen la proactividad y la vinculación de comunidades bajo objetivos comunes en ánimo al mejoramiento de problemas sociales; aunque es necesario reconocer, por lo visto en el BMFS, que los liderazgos individuales son de gran valía para la promoción, desarrollo y evaluación de acciones de eficacia colectiva. Algunos contextos pueden poseer estas características (caso BMFS), por el contrario hay otros en donde se evidencian carencias (caso BAN). Lógicamente, dejar todo en manos del liderazgo sería un reduccionismo, puesto que los colectivos también deben poseer características de resiliencia comunitaria (autoestima colectiva, identidad cultural y humor social) para lograr mejorías.

Finalmente, de lo dicho pueden formularse 3 conclusiones: la primera, es que la teoría de la eficacia colectiva necesita de insumos propios del contexto empírico al que se aproxima el investigador, para ser más potente en su alcance explicativo. La presente investigación la utilizó para comprender todas las acciones en conjunto que dan al BMFS rasgos particulares de comunidad, diferenciándolo de barrios homólogos. No obstante, hubiese sido imposible hacer un buen ejercicio reflexivo si no se hubiese tenido en cuenta la teoría intermedia de los espacios defendibles y el concepto de espacios residenciales multifamiliares. Esta misma tendencia se observó con las investigaciones recientes sistematizadas en el estado de la cuestión. Es muy importante, que futuros trabajos traten de generar un diálogo armónico entre la teoría y la praxis, generando así aportaciones de calidad a las ciencias sociales como disciplinas acumulativas. Esta investigación trató de hacer lo propio frente a lo afirmado.

Lo segundo, es que si bien, la presente investigación tuvo un carácter local, puede ser de utilidad para el análisis de otros contextos latinoamericanos, puesto que en la literatura estudiada, se evidencian aproximaciones donde se examinan ciudades enteras en su conjunto, sobre todo cuando se buscan ejercicios de espacio defendible. Lo ventajoso de las aproximaciones de corte microsociológico, es que permiten revisar con mayor detalle las maniobras de la agencia, sistematizando así, de forma objetiva, 
accionares que pueden ser emulados en la práctica política, mejorando las condiciones de otros microcontextos dentro de la ciudad, provincia o país objeto de estudio. Se considera entonces, que la aportación del artículo a la discusión latinoamericana se centra en la metodología cualitativa utilizada y en el enfoque del abordaje empleado.

En relación con lo aportado, se considera como tercera y última conjetura que el estímulo desde lo político de este tipo de acciones, se pueden configurar como respuestas a problemas de corte social, económico y cultural, en los cuales los microcontextos son capaces de formular soluciones a diferentes disyuntivas desde su iniciativa o de manera mancomunada con la institucionalidad, configurándose así como prácticas de necesaria reflexión académica para el diseño de políticas pública de convivencia más novedosas.

\section{REFERENCIAS}

Anguiano, R. V. (2016). La delincuencia urbana en una ciudad media mexicana. Carta Económica Regional, (115), 25. Recuperado de http://www.cartaeconomicaregional.cucea.udg.mx/index.php/ CER/article/viewFile/5673/5203

Alcaldía de Santiago de Cali. (2007a). Visión Cali. Iniciativas de convivencia y seguridad. Recuperado de http://www.cali. gov.co/publico2/documentos/observatorio/INICIATIVASCOM.pdf

Alcaldía de Santiago de Cali. (2007b). Informe Enero-Octubre 2007. Recuperado de http://www.cali.gov.co/publico2/ documentos/observatorio/documentos/ VisionCali2007.pdf

Alcaldía de Santiago de Cali (2017). Anexo 5: Ficha de caracterización socioeconómica de los barrios de Santiago de Cali (Diagnóstico descriptivo). Comuna 4, Barrio Marco Fidel Suárez. Recuperado de http://www.cali.gov.co/participacion/ publicaciones/135173/comuna-4/gen Pagdoc1588=4

Alcaldía de Santiago de Cali (s. f.). Mapa de la comuna 4, Santiago de Cali. Recuperado de www.cali.gov.co/publico2/comunas/imagenes/calimap4.pdf

Belalcázar, A. (2012). Cali entre las 11 ciudades más peligrosas del mundo. $\mathrm{Ca}$ liescribe. Recuperado de http://caliescribe.com/es/reporte-urbano/2012/01 /14/1913-cali-11-ciudades-mas-peli grosas-del-mundo

Borré, C., Castro, J., Franco, R., López, J., Otero, D., Pizarro, M., Ramírez, C., Ramírez, O. E., Riascos, S., Saavedra, J., y Castillo, M. (2014). Las pandillas y las oficinas de cobro: una relación de agencia. El Observador Regional. (29). Colombia: Universidad del Valle. Pp. 1-4. Recuperado de http://elobservador. univalle.edu.co/OBS_29.pdf

Bourdieu, P. (1991). El sentido práctico. Buenos Aires, Argentina: Siglo XXI.

Cali Como Vamos. (2017). Como vamos en Seguridad 2017. Recuperado de http:// docs.wixstatic.com/ugd/ba6905_90b3792ceec04969943d74a3fa47c183.pdf

Cali entre las 10 ciudades más peligrosas del mundo. (2015). Caracol Radio. Recuperado de http://caracol.com.co/radio/2015/01/20/nacional/1421770800_596217.html

Cali es la ciudad que presenta la situación más grave de violencia juvenil. (Noviembre 6 de 2014). El País. Recuperado de http://www.elpais.com.co/judicial/calies-la-ciudad-que-presenta-la-situacionmas-grave-de-violencia-juvenil.html 
Cali y Palmira otra vez entre las primeras 10 ciudades más peligrosas del mundo. (Abril 26 de 2016). Las2Orillas. Recuperado de https://www.las2orillas.co/caliy-palmira-otra-vez-entre-las-10-ciudades-mas-peligrosas-del-mundo/

Consejo Ciudadano Para la Seguridad Pública y la Justicia Penal de México. (2017). Metodología del ranking (2016) de las 50 ciudades más violentas del mundo. Recuperado de https:// www.seguridadjusticiaypaz.org.mx/ biblioteca/prensa/download/6-prensa/239-las-50-ciudades-mas-violentas-del-mundo-2016-metodologia

El Espectador. (2013). Pandillas en Cali. Recuperado de https://www.elespecta dor.com/noticias/infografia/pandillas -cali-articulo-413884

Esquivel Corella, F. (2013). Lineamientos para diseñar un estado de la cuestión en investigación educativa. Educación, 37(1). Recuperado de https://revistas. ucr.ac.cr/index.php/educacion/article/ view/10631/10028

Fernández-Toribio García, A. (2015). Comunidad y prevención delictiva (tesis de Licenciatura en Criminología). Universidad Autónoma de Barcelona, España. Recuperado de https://ddd.uab.cat/ pub/tfg/2015/133311/TFG_afernandeztoribiogarcia.pdf

Galaviz, T. (2014). La complejidad en la violencia en Morelos. En Aguayo, S. (Ed.). Atlas de la seguridad y violencia en Morelos. Cuernavaca, México: Universidad Autónoma del Estado de Morelos.

Galtung, J. (1998). Tras la violencia, 3R: reconstrucción, reconciliación, resolución. Afrontando los efectos visibles e invisibles de la guerra y la violencia. Bilbao, España: Gernika Gogoratuz.
Giménez, G. (2017). Materiales para una teoría de las identidades sociales. Frontera norte, 9(18), 9-28. Recuperado de http://lie.upn.mx/docs/Diplomados/ LineaInter/Bloque1/Identidad/Lec1.pdf Gutiérrez Rivera, R. A. (2017). Prevención del crimen a través del diseño ambiental recuperación del espacio público en el periodo 1998-2002 en Bogotá (tesis de especialización en Administración en Seguridad). Universidad Militar Nueva Granada, Bogotá D. C., Colombia. Recuperado de http://repository.unimilitar.edu.co/bitstream/10654/16647/1/GutierrezRiverarafaelAlfonso.2017.pdf

Liceaga, G. (2013). El concepto de comunidad en las ciencias sociales latinoamericanas: apuntes para su comprensión. Cuadernos Americanos, 145(3), pp. 57-85. Recuperado de http://www.cialc.unam. $\mathrm{mx} /$ cuadamer/textos/ca145-57.pdf

López-Alfaro, P., Osorio-González, F., Gallegos-Araya, V., y Cáceres-Cadena, M. D. (2016). Liderazgo escolar y eficacia colectiva en escuelas públicas de Bogotá. Magis. Revista Internacional de Investigación en Educación, 9(18). Recuperado de http://dx.doi.org/10.11144/Javeriana. m9-18.leec

Mateo, A., y Quintero, J. (2013). El concepto de comunidad y el trabajo social. Espacios Transnacionales, (1), 4-10. Recuperado de http://espaciostransnacionales.org/ wp-content/uploads/2014/10/1-Conceptotrabajosocial1.pdf

Montero, M. (2006). Teoría y práctica de la psicología comunitaria: la tensión entre comunidad y sociedad. Buenos Aires, Argentina: Paidós. Recuperado de http://www. psicosocial.net/grupo-accion-comunitaria/centro-de-documentacion-gac/ fundamentos-y-teoria-de-una-psico- 
logia-liberadora/psicologia-comunitaria/542-teoria-y-practica-de-la-psicologia-comunitaria-la-tension-entre-comunidad-y-sociedad-1o-parte/ file

Munist, M., Kotliarenco, M. A., Santos, H., Suárez Ojeda, E. N., Infante, F., y Grotberg, E. (1998). Manual de identificación y promoción de la resiliencia en niños y adolescentes. Organización Panamericana de la Salud, Organización Mundial de la Salud, Fundación W. K. Kellogg, Autoridad Sueca para el Desarrollo Internacional (ASDI).

Muñoz, F. (2004). Paz imperfecta. En Mario López Martínez (Dir.), et al. Enciclopedia de Paz y Conflictos: L-Z. Edición especial. Granada, España: Editorial Universidad de Granada.

Naciones Unidas. (2006). Dinámica reciente de la violencia en Cali. Recuperado de http://www.acnur.org/fileadmin/scrip ts/doc.php?file=fileadmin/news_impor ted_files/COI_1440

Newman, O. (1972). Defensible Space. New York, NY: McMillan Co.

Maldonado Gómez, M. C., y Rincón Salazar, M. T. (2007). Acerca de los motivos para vivir en espacios residenciales multifamiliares. Prospectiva. Revista de Trabajo Social e Intervención Social, (12), 147-180. Recuperado de http://revistaprospectiva.univalle.edu.co/index.php/ prospectiva/article/view/959

Molero, M. N. (2014). Seguridad y ciudadanía: necesidad de un "pacto de convivencia". Boletín $C F+S$, (8). Recuperado de http://polired.upm.es/index.php/ boletincfs/article/viewFile/2567/2632

Olavarría Gambi, M., Tocornal Montt, X., Manzano Chávez, L., y Fruhling Erlich, H. (2008). Crimen y violencia urbana.
Aportes de la ecología del delito al diseño de políticas públicas. Revista Invi, 23(64). Recuperado de http://revistainvi.uchile.cl/index.php/INVI/article/ view/4/957

Ortega, J. (2010). Ciudad Juárez, por segundo año consecutivo, la ciudad más violenta del mundo. Consejo Ciudadano para la Seguridad Pública y la Justicia Penal. Recuperado de http://www.seguridadjusticiaypaz.org.mx/sala-de-prensa/58cd-juarez-por-segundo-ano-consecutivo-la-ciudad-mas-violenta-del-mundo

Pérez, P. J. I. R., Silva, A. P., López, E. J., y Mesa, L. S. R. (2012). Eficacia colectiva y percepción de inseguridad en población joven colombiana: un análisis desde la salud comunitaria. Recuperado de http://congresopsicologiauptc.com/ inicio/wp-content/uploads/2015/04/Memorias-VI-Congreso.pdf\#page $=217$

Porretta, D. (2010). Barcelona, ¿ciudad del miedo?: urbanismo "preventivo" y control del espacio público. DC. Revista de crítica arquitectónica, (19-20), 183-192. Recuperado de https://upcommons.upc. edu/bitstream/handle/2099/10607/09_ PORRETTA.pdf

Rao, S. (2016). A Measure of community. Public Open Space Sustainable Development Goal. Notion Press. Recuperado de https://books.google.com.mx/books?i$\mathrm{d}=\mathrm{mCKeDAAAQBAJ} \& \mathrm{pg}=$ PT176\&redir_esc $=\mathrm{y} \# \mathrm{v}=$ onepage $\& \mathrm{q} \& \mathrm{f}=$ false

Real Academia Española. (2017). Definición de la palabra "cuadra". Recuperado de http://dle.rae.es/?id=BPCVtaV

Ruíz Perales, Elvira. (2014). Descomposición social. Diario MX. Recuperado de http://diario.mx/Nvo_Casas_Grandes /2014-01-11_1c4aba40/descomposi cion-social/ 
Ruiz Pérez, J. I. (2015). Resiliencia comunitaria: propuesta de una escala y su relación con indicadores de violencia criminal. Pensamiento Psicológico, 13(1). Recuperado de http://www.scielo.org.co/scielo. php?pid=S165789612015000100009\&script=sci_arttext\&tlng=es

Sampson, R. (2004). Vecindario y comunidad: eficacia colectiva y seguridad ciudadana. Traducción de Elena Larrauri Pijoan del original "Neighbourhood and community. Collective efficacy and community safety". Publicado en: New Economy, pp. 106-113. Recuperado de http://repositorio.gobiernolocal.es/ xmlui/bitstream/handle/10873/856/claves06_10_sampson.pdf?sequence $=1$

Seis ciudades de Colombia entre las más peligrosas del mundo. (2013). El Espectador. Recuperado de https://www. elespectador.com/noticias/elmundo/seis-ciudades-de-colombia-entre-mas-violentas

Tejeda, D. (2006). Estrategias comunitarias de convivencia y seguridad: estudio exploratorio en los barrios de Cali. Colombia. Producción del Observatorio Social. Alcaldía de Santiago de Cali. Visión Cali, 2(2), pp. 1-22. Recuperado de http://www.cali.gov.co/publico2/documentos/observatorio/documentos/1-10. pdf

Valenzuela Aguilera, A. (2012). La eficacia colectiva como estrategia de control social del espacio barrial: evidencias desde Cuernavaca, México. Revista Invi, 27(74), 187-215. Recuperado de https://scielo.conicyt.cl/scielo.php?pi$\mathrm{d}=\mathrm{S} 071883582012000100006 \&$ script $=\mathrm{s}-$ ci_arttext 